\title{
The Excitatory Effect of Cholecystokinin on Colonic Motor Function via Cholecystokinin 1 Receptor
}

\author{
Jae Yeoul Jun \\ Department of Physiology, College of Medicine, Chosun University, Gwangju, Korea
}

\author{
Article: Mechanism of action of cholecystokinin on colonic motility in isolated, vascularly perfused rat colon \\ Ko BS, Han JH, Jeong J, et al \\ (J Neurogastroenterol Motil 2011;17:73-81)
}

Cholecystokinin (CCK) was first described over 70 years ago as a putative hormone that caused gallbladder contraction in response to fat in the small intestine. ${ }^{1}$ The actions of CCK include stimulation of exocrine and endocrine secretion, motility and growth in the gastrointestinal tract, and regulation of satiety, anxiety, pain and behavior in the central and peripheral nervous systems. It is therefore a prototype of a class of agents known as brain-gut peptides, functioning both as a neuropeptide and as a gut hormone. ${ }^{2,3}$ There are 2 principal sources of CCK: endocrine I cells in the duodenal wall that are in contact with the lumen of the intestine, and peptidergic nerves both in the enteric nervous system and in the central nervous system. In the periphery, CCK-containing neurons are found in the myenteric plexus, submucosal plexus, muscle layers of the small intestine and colon, the celiac plexus and the vagus nerve. ${ }^{4}$

Receptors for CCK were first characterized on pancreatic acinar cells and identified as CCK type A receptors (CCK-A or $\mathrm{CCK}_{1}$ ), with the subsequent discovery in the same year of a second receptor with a different pharmacology in the brain, CCK type $\mathrm{B}$ receptors (CCK-B or $\mathrm{CCK}_{2}$ ). These 2 types of CCK receptor could be pharmacologically distinguished on the basis of their affinity for the agonists $\mathrm{CCK}$ and gastrin. $\mathrm{CCK}_{1}$ are highly selective for analogs of $\mathrm{CCK}$, whereas $\mathrm{CCK}_{2}$ have similarly high affinity for both analogs of CCK and gastrin. ${ }^{5}$

CCK has been known to affect human colonic motility for more than 3 decades. ${ }^{6}$ In spite of the large number of functional investigations since then, only 1 study has provided data regarding the distribution of $\mathrm{CCK}_{1}$ receptors in human colon. ${ }^{7}$ It is well known that CCK affects colonic motility by 2 fundamentally different pathways: acting on neurons in the myenteric plexus and directly on the smooth muscle cells. Cholinergic regulation is involved in the pathway acting on neurons. Interestingly, it was suggested that CCK stimulate the release of peptide YY (PYY) which increases the colonic motility in rat colon. ${ }^{8}$

However, there are no crucial reports whether CCK act on colonic motility by regulating cholinergic neurons or stimulating the release of PYY. In this issue of the Journal of Neurogastroenterology and Motility, Ko et al investigated the effects of CCK on

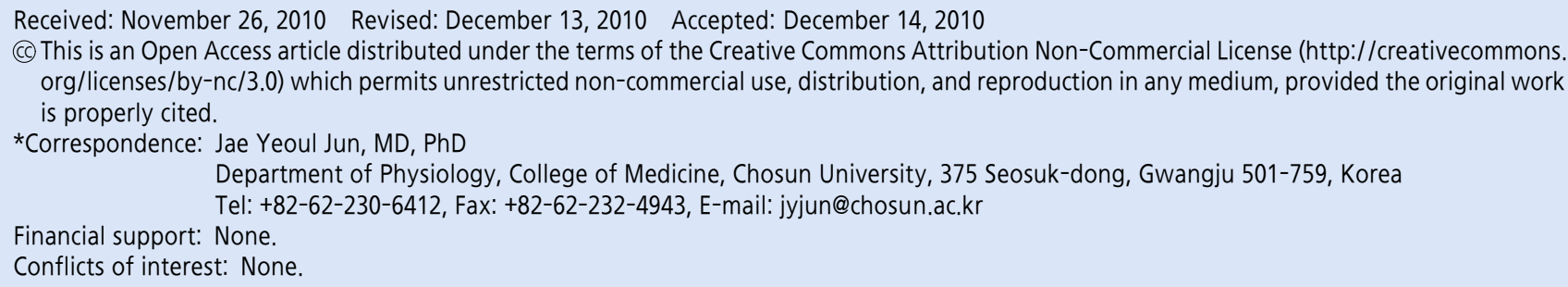


colonic motility, the involvement of PYY release and cholinergic regulation on CCK-induced action in isolated, vascularly perfused rat colon. They found that CCK increased the colonic motility in proximal and distal colon dose-dependently. Also, they could see the increasing effect on colonic motility. To find the $\mathrm{CCK}$ receptor subtype, they used loxiglumide, a specific $\mathrm{CCK}_{1}$ receptor antagonist and found loxiglumide blocked the CCK-induced action on colonic motility. In previous reports, there are many suggestions that $\mathrm{CCK}_{1}$ receptor only involves for $\mathrm{CCK}$ action in colon, gallbladder, pancreas and stomach of animals and human. ${ }^{9,10}$ There is a thread of connections between previous reports and this result. And they could find CCK to stimulate the release of PYY in proximal and distal colon dose-dependently. Furthermore, CCK- or PYY-induced action on colonic motility was inhibited by pretreatment with atropine. These mean that CCK can act on colonic motility by stimulating PYY release or by cholinergic pathway. Interestingly, it was already suggested that the release of PYY could be stimulated by CCK or cholinergic regulation in proximal colon whereas by direct mechanism in distal colon. ${ }^{9}$ So, they concluded that $\mathrm{CCK}_{1}$ receptor, $\mathrm{PYY}$ release and cholinergic input are closely related with CCK-induced action on colonic motility.

The acting mechanism of CCK on colonic motility appears more intricate because of the wide-spread localization in gastrointestinal tract. Therefore, finding the exact mechanism of CCKinduced action on gastrointestinal motility must be further studied in the future.

\section{References}

1. Ivy AC, Oldberg E. A hormone mechanism for gallbladder contraction and evacuation. Am J Physiol 1928;86:599-613.

2. Crawley JN, Corwin RL. Biological actions of cholecystokinin. Peptides 1994;15:731-755.

3. Noble F, Wank SA, Crawley JN, et al. International union of Pharmacology. XXI. Structure, distribution, and functions of cholecystokinin receptors. Pharmacol Rev 1999;51:745-781.

4. Liddle RA. Cholecystokinin cells. Annu Rev Physiol 1997;59:221242.

5. Wank SA. Cholecystokinin receptors. Am J Physiol 1995;269(5 Pt 1):G628-G646.

6. Harvey RF, Read AE. Effects of cholecystokinin on colonic motility and symptoms in patients with the irritable bowel syndrome. Gut 1972;13:837-838.

7. Rettenbacher M, Reubi JC. Localization and characterization of neuropeptide receptors in human colon. Naunyn Schmiedebergs Arch Pharmacol 2001;364:291-304.

8. Plaisancié P, Bernard C, Chayvialle JA, Cuber JC. Release of peptide $\mathrm{YY}$ by neurotransimitters and gut hormones in the isolated, vascularly perfused rat colon. Scand J Gastroenterol 1995;30:568-574.

9. Niederau C, Heintges T, Rovati L, Strohmeyer G. Effects of loxiglumide on gallbladder emptying in healthy volunteers. Gastroenterology 1989;97:1331-1336.

10. Grider JR, Makhlouf GM. Distinct receptors for cholecystokinin and gastrin on muscle cells of stomach and gallbladder. Am J Physiol 1990;259(2 Pt 1):G184-G190. 